\title{
Note from the editor
}

\author{
"Begin now to do something that has long been a dream, something that makes you approach \\ each new day as a journey to accomplish what you want and desire."
}

- Byron Pulsifer

In the editorial of the first edition of 2020, I referred to the Spanish Flu, and the fact that we were in the first phases of a national lockdown. And in the second edition, I expressed my concern on the downturn in the economy, and the impact on the sectors where Industrial Engineers work. Never did we realise that it would be such an extended disruption! I also thought that this creates new opportunities, and Industrial Engineering is well positioned to tackle and succeed with these opportunities.

A year later, we had just ended yet another lockdown, with the $3^{\text {rd }}$ wave now diminishing here in South Africa. But there is a light at the end of the tunnel:

- The vaccination program in our country is at last supplying more vaccines. And statistics show that severe illness and deaths in those that are vaccinated, are mostly eliminated.

- $\quad$ The economy proved to be more resilient than expected, mostly due to new ways of working and innovation. This is causing a paradigm shift in a lot of industries, and who best again than Industrial Engineers to take this forward.

This is well illustrated with what has been happening in the career marketplace recently, with Capitec, FNB and ABSA competing for the skills that Industrial Engineering offers. And more is coming.

Despite the uncertain times, this edition contains 10 articles, of which five are from international authors outside South Africa.

If you have suggestions on how we can take this journal forward, please let me know.

Corne Schutte

Editor 